\title{
A case of spinal epidural venous malformation with mediastinal extension: management with combined surgery and percutaneous sclerotherapy
}

\author{
Gurpreet S. Gandhoke, MD, ${ }^{1}$ Sabri Yilmaz, MD, ${ }^{2,5}$ Lorelei Grunwaldt, MD, ${ }^{3,5}$ \\ Ronald L. Hamilton, MD, ${ }^{4}$ David J. Salvetti, MD, ${ }^{1}$ and Stephanie Greene, MD ${ }^{1,5}$ \\ Departments of ${ }^{1}$ Neurological Surgery, ${ }^{2}$ Interventional Radiology, ${ }^{3}$ Plastic and Reconstructive Surgery, and ${ }^{4}$ Pathology, and
5Vascular Anomalies Center, Children's Hospital of Pittsburgh, Pennsylvania
}

\begin{abstract}
While spinal epidural arteriovenous malformations, fistulas, and shunts are well reported, the presence of a venous malformation in the spinal epidural space is a rare phenomenon. Herein, the authors report the clinical presentation, imaging findings, pathological features, and the outcome of surgical and percutaneous interventional management of a mediastinal and spinal epidural venous malformation in a young woman who presented clinically with neurogenic claudication from presumed venous hypertension precipitating the formation of a syrinx. The patient underwent a C6-T5 osteoplastic laminectomy for decompression of the spinal canal and subtotal resection of the epidural venous malformation, followed by percutaneous sclerotherapy of the mediastinal and residual anterior spinal venous malformation. She developed transient loss of dorsal column sensation, which returned to baseline within 3 weeks of the surgery. A 6-month postoperative MRI study revealed complete resolution of the syrinx and the mediastinal venous malformation. Twelve months after the surgery, the patient has had resolution of all neurological symptoms with the exception of her premorbid migraine headaches. A multidisciplinary approach with partial resection and the use of percutaneous sclerotherapy for the residual malformation can be used to successfully treat a complex venous malformation.
\end{abstract}

http://thejns.org/doi/abs/10.3171/2015.9.PEDS15341

KEY WORDS venous malformation; epidural; syringomyelia; mediastinal; sclerotherapy; spine; vascular disorders

$\mathrm{V}$ ASCULAR anomalies are disorders of the endothelium that can affect capillaries, arteries, veins, or lymphatics. The field of vascular anomalies is confusing because numerous types of vascular anomalies exist and many practitioners use imprecise terminology. For instance, the term "cavernous hemangioma" was used to describe venous malformations. ${ }^{9}$ Vascular lesions involving the spinal canal are uncommon and are mostly located in the intradural space. They account for approximately $6 \%-7 \%$ of all spinal intradural masses. ${ }^{4,15,18}$ While spinal epidural arteriovenous malformations, fistulas, and shunts are extensively reported, spinal extradural venous malformations are rare. . $14,23,26$ To the best of our knowledge, this is the first report of a spinal epidural and paraspinal venous malformation precipitating the formation of a syrinx, which was managed in a multidisciplinary fashion with surgery and subsequent percutaneous sclerotherapy. The clinical manifestations, imaging and pathological findings, and outcomes of surgery and percutaneous interventional sclerotherapy are discussed with a review of the literature.

\section{Case Report}

An 18-year-old female patient with a known Chiari malformation and a histopathologically proven mediastinal venous malformation presented in October 2013 with the new onset of numbness, paresthesias, and exertional weakness in her arms and legs, as well as a dramatic increase in the severity of her preexisting headaches. The headaches, which improved with sleep, were migrainous, with associated phono- and photophobia, nausea, and vomiting. The weakness and pain developed after the use of an extremity for a period of time, such as after walking a distance or writing during a class. 

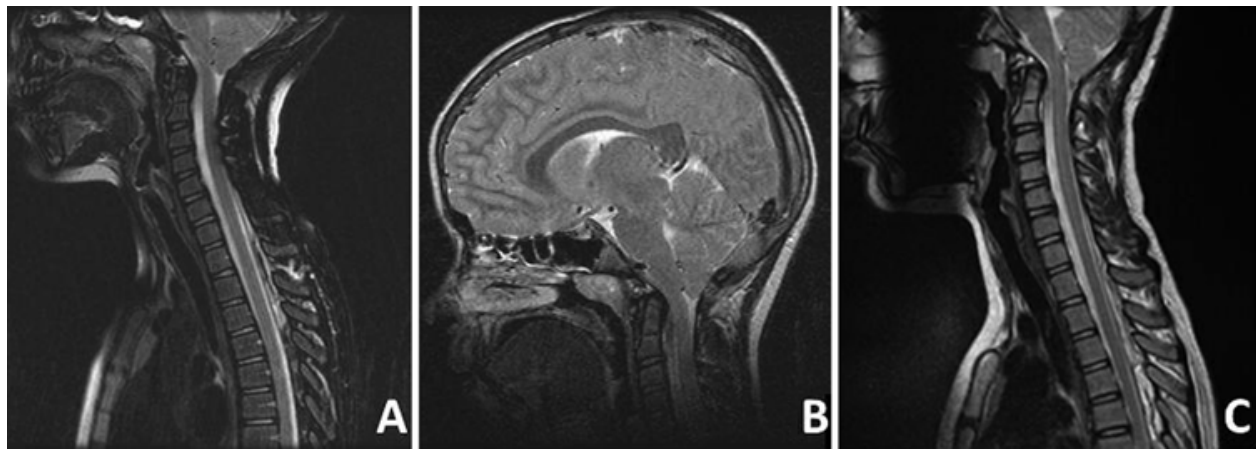

FIG. 1. Preoperative and postoperative sagittal T2-weighted MR images demonstrating Chiari malformation before and after decompression in 2004 (A), 2005 (B), and 2007 (C). Note the absence of syrinx in panel C.

The patient had first presented to the pediatric general surgery clinic with a persistent cough and neck spasms when she was 8 years old. Chest radiography and CT scanning demonstrated a posterior mediastinal mass. In May 2004, she underwent exploratory video-assisted thoracoscopic surgery for biopsy of this mass, which revealed the diagnosis of a venous malformation. MRI before an open attempt at resection demonstrated this mass to be in continuity with a circumferential epidural mass extending through the T-1 and T-2 neural foramina on the right. Her chief complaint was relieved after the second surgery, though significant hemorrhage and a right Horner syndrome complicated this intervention. In addition, the MRI showed an (at that time) incidental finding of a Chiari I malformation with descent of the cerebellar tonsils by 9 $\mathrm{mm}$ (Fig. 1A). There was no associated syringomyelia or other intracranial abnormality. She developed exertional headaches and nuchal pain in 2005 (Fig. 1B) and underwent a Chiari decompression (3-cm suboccipital craniectomy, C-1 laminectomy, and generous duraplasty) in March of 2005 (Fig. 1C). Since 2007, she has been undergoing constant follow-up with the neurology clinic for management of migraine headaches. She underwent annual MRI to assess the vascular malformation for interval change. She remained asymptomatic from the residual venous malformation until October 2013.

An MRI in 2013 demonstrated the residual mediastinal venous malformation with stable extension into the epidural space of the spinal canal (Fig. 2A and C). The Chiari malformation appeared adequately decompressed, although the subarachnoid space was effaced (Fig. 2B). Moderate epidural lipomatosis was present inferior to the venous malformation (Fig. 2D). A new syrinx (measuring $4 \mathrm{~mm}$ in largest diameter at C-7, and $3 \mathrm{~mm}$ in largest diameter at T-2 and T-5) extending from C-6 to T-5 was identified, and was hypothesized to have developed secondary to venous hypertension restricting the egress of CSF from the central canal, direct compression of the spinal cord by the venous malformation, or effacement of the subarachnoid space by the venous malformation (Fig. 2A and C). Presyrinx was present above and below the syrinx. Notably, she had been receiving oral contraceptives for amenorrhea 6 months prior to developing her neurological complaints.

A spinal angiogram was negative for arterial supply to the malformation from the aorta or intercostal, subclavian, or vertebral arteries, excluding a fast-flow lesion. Results of a D-dimer test were normal, and evaluation by a hematologist revealed no evidence of a hypercoagulable state. Because of the patient's neurogenic claudication in the setting of a new syrinx, surgical intervention was suggested. The lack of symptoms referable to the Chiari malformation led to the recommendation of a multilevel decompressive laminectomy with resection of the dorsal and lateral components of the epidural mass, with the goals of both direct decompression of the thecal sac and normalization of the venous pressure within the spinal canal to allow resolution
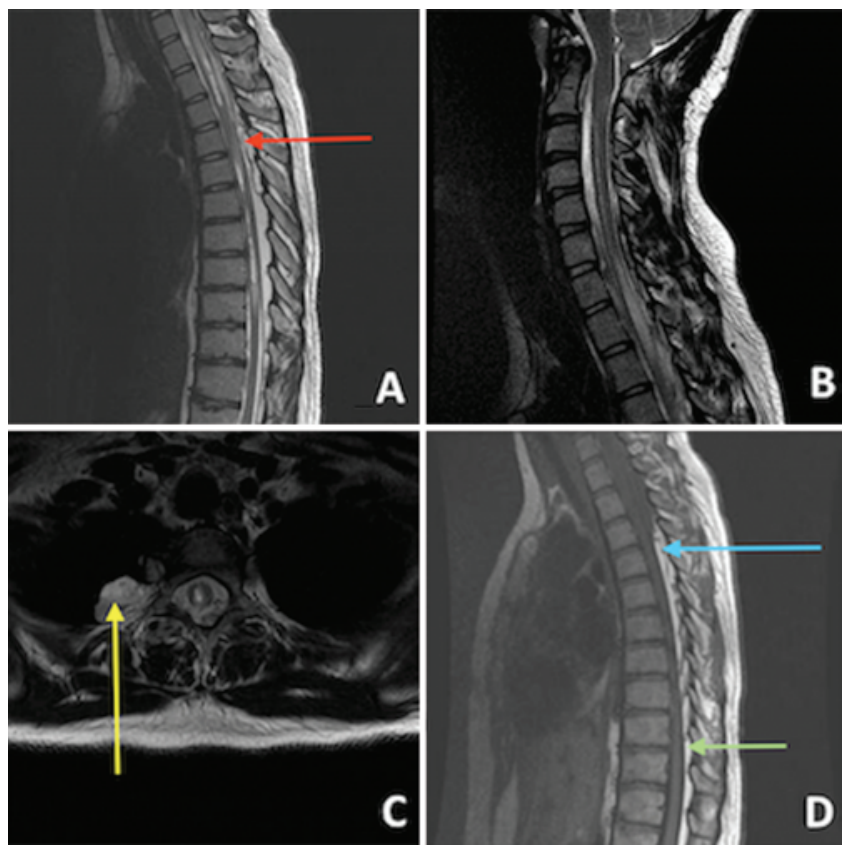

FIG. 2. A: Sagittal T2-weighted MR image of the cervicothoracic spine demonstrating epidural vascular prominence (arrow) and interval development of a syrinx. B: Sagittal T2-weighted MR image of the cervical spine demonstrating decompressed Chiari malformation with adequate CSF present at the cervicomedullary junction. C: Axial T2-weighted MR image demonstrating posterior mediastinal mass (arrow) and syrinx. D: Sagittal T1-weighted MR image demonstrating epidural lipomatosis (green arrow) caudal to the venous malformation (blue arrow). Figure is available in color online only. 
of the syrinx. In February 2014, the patient underwent a C6-T5 osteoplastic expansile laminectomy to expand her spinal canal, with resection of the venous malformation along the length and width of the exposure. The mass was fibrous and filled with large, thin-walled vascular channels that were readily compressible. A single phlebolith was identified. A lipomatous component was present at the inferior aspect of the exposure. The resection was accompanied by an expected significant blood loss of $2 \mathrm{~L}$, and a massive transfusion protocol was used intraoperatively to maintain hemostasis. The thecal sac began to pulsate at the termination of the resection, evidence that the normal flow of CSF had been restored. Neither the ventral component nor the mediastinal component of the malformation could not be resected from this posterior approach. The pathological features of the resected specimens in 2004 and 2014 are shown in Fig. 3.

The mediastinal mass contained dense fibrous tissue with numerous dilated venous spaces (Fig. 3A). An elastic-trichrome stain showed that these vascular spaces were not arteries, because they lacked an internal elastic lamina (Fig. 3B). Some areas of the resection showed increased numbers of thin-walled venous channels (Fig. 3C). The walls surrounding these venous spaces sometimes contained focal smooth muscle (Fig. 3D). The pathology specimen from 2014 showed a fibrous nodule (Fig. 3E) with a wall made of collagen and circumferential smooth muscle tissue (Fig. 3F) with no recanalization, consistent with a thrombosed vein.
Postoperatively, the patient was relieved of the neurogenic claudication but experienced altered dorsal column sensation in her lower extremities, presumably secondary to epidural coagulation of the malformation, decompression of the spinal cord, or altered CSF dynamics. She was placed on a regimen of gabapentin therapy. The patient was discharged to a pediatric rehabilitation institution for reconditioning. She wore a Minerva brace at all times when out of bed to promote spinal fusion and minimize the chances of postlaminectomy kyphosis. Within a month after her surgery, while in rehabilitation, the patient developed transient bilateral abducens nerve palsies. Her longstanding amenorrhea resolved, and her headaches improved. We speculate that the expansion of the intracranial subarachnoid space with decompression of the pituitary gland that was apparent on a postoperative brain MRI may have contributed to the resolution of her amenorrhea (Fig. 4).

Percutaneous sclerotherapy was suggested to obliterate the residual venous malformation and to prevent growth of the malformation and possible recurrence of neurological symptoms. Two months after the spinal surgery, the right mediastinal/paravertebral venous malformation at the level of the T1-2 vertebral foramina was accessed using a 22-gauge 3.5-inch long spinal needle under CT fluoroscopic guidance. The venous malformation was injected with $7 \mathrm{ml}$ of iopamidol 300 (Isovue, Bracco Diagnostics Inc., BIPSO $\mathrm{GmbH}$ ) and serial CT venograms were obtained. The contrast flowed toward the epidural space through the T1-2 vertebral foramina. Following the opacification

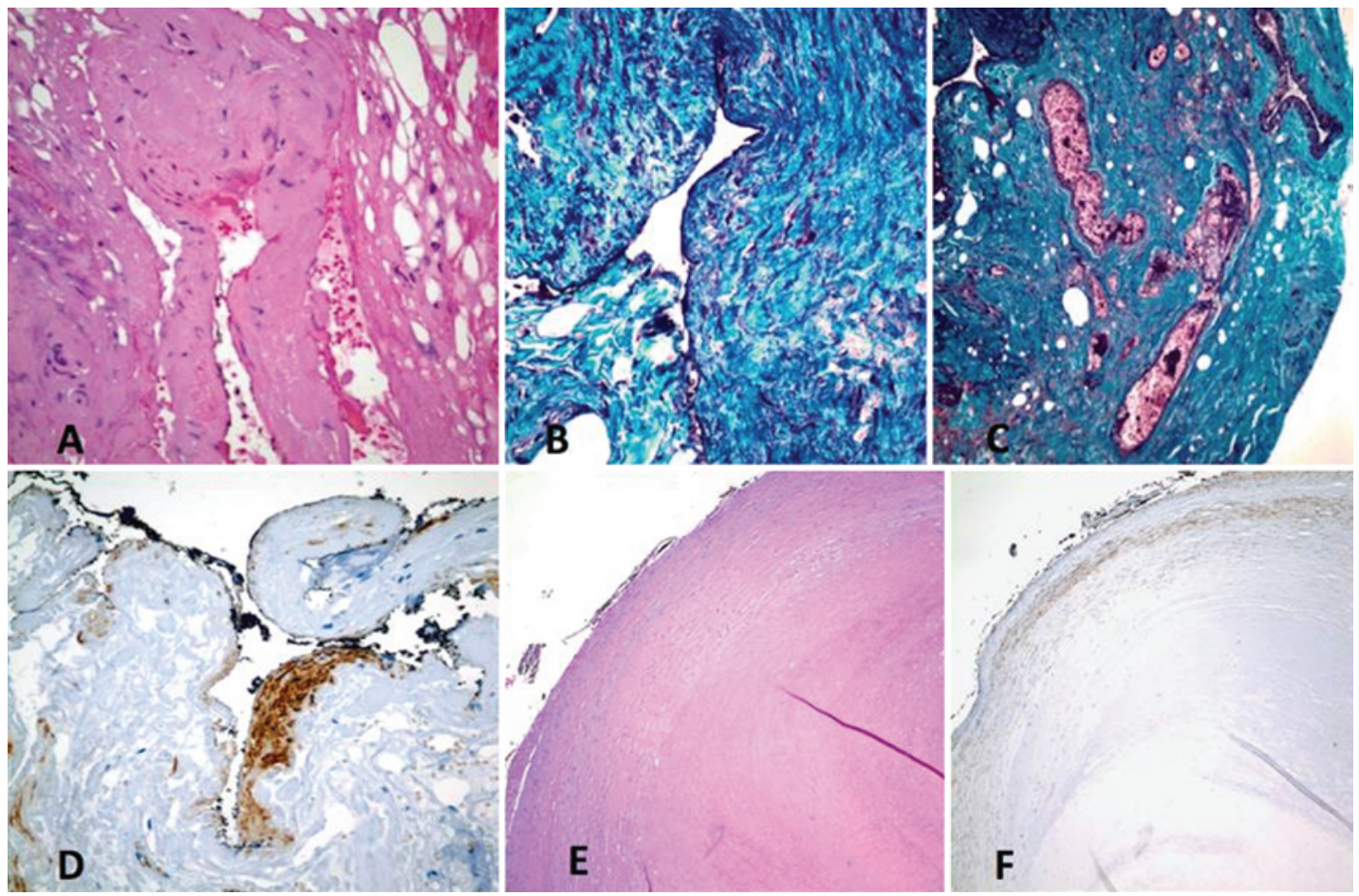

FIG. 3. Vascular malformation from 2004 (A-C) and 2014 (D-F). H \& E-stained sections of the lesion in 2004 revealed no abnormal arteries, but numerous abnormal sinusoidal blood vessels were present (A). An elastic-trichrome stain shows no internal elastic lamina (B) and increased venous complexity in some areas (C). Immunostaining for smooth muscle actin shows these channels to have focal smooth muscle (D). Tissue from the 2014 surgery shows a fibrous nodule (E) that also showed small amounts of smooth muscle in the outer wall, indicating a thrombosed vein (F). Original magnification $\times 400(A-D) ; \times 200(E$ and F). Figure is available in color online only. 

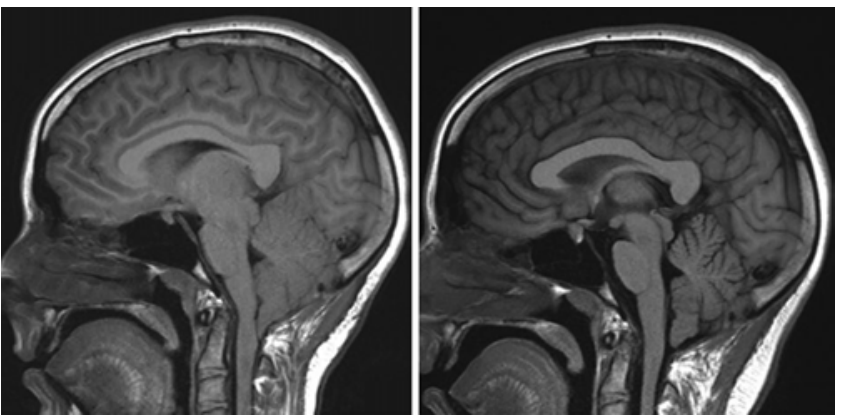

FIG. 4. Sagittal T1-weighted brain MR images obtained preoperatively (left) and postoperatively (right), with increased subarachnoid space apparent after treatment of the epidural venous malformation.

of the mediastinal and epidural venous malformations, a mixture of $4 \mathrm{ml}$ of $3 \%$ sodium tetradecyl sulfate (Sotradecol, Mylan Institutional) and $4 \mathrm{ml}$ of iopamidol 300 was injected into the venous malformation and serial images were obtained, showing good opacification and coverage of the epidural venous malformation (Fig. 5).

An MRI obtained 6 months after surgery revealed the complete resolution of the syrinx (Fig. 6A and B). The mediastinal mass was no longer apparent (Fig. 6C). The patient's diplopia and sensation had returned to normal. In the 18 months since surgery, the patient has been weaned from her brace. She has had progressive bony fusion of her expansile multilevel laminectomy and no development of kyphosis. Her headaches have been minor, intermittent, and easily controlled with over-the-counter medication. She has been weaned off of the gabapentin. She continues to receive riboflavin, magnesium oxide, and Topamax for migraine prophylaxis.

\section{Discussion}

\section{Terminology}

Mulliken and Glowacki proposed a biological classification of vascular anomalies, and correlated their clinical features, natural history, and cellular characteristics. ${ }^{19}$ This classification was adopted by the International Society for the Study of Vascular Anomalies (ISSVA), and is now recognized worldwide as an official system for classification of vascular anomalies. It classified vascular anomalies into 2 subgroups: neoplasms and malformations. Avascular malformation is defined as a congenital or developmental morphogenic anomaly of various vessels with a normal growth rate and normal endothelial turnover; this category has been subdivided into 2 subgroups: slow- or low-flow malformations, and fast- or high-flow malformations. The former include capillary, venous, lymphatic, and mixed malformations. The previous terms "cavernous hemangioma" and "cavernous malformation," and "cavernous angioma" have been abandoned (though they are still widely used in clinical practice), and the new term "venous malformation" is used in the ISSVA classification. The reports in the literature describing "cavernous malformations" in the epidural spinal space are likely reports on venous malformations. Pure nonvertebral spinal epidural venous malformations are relatively rare, and about 100 cases have been reported in the literature. ${ }^{25,30}$
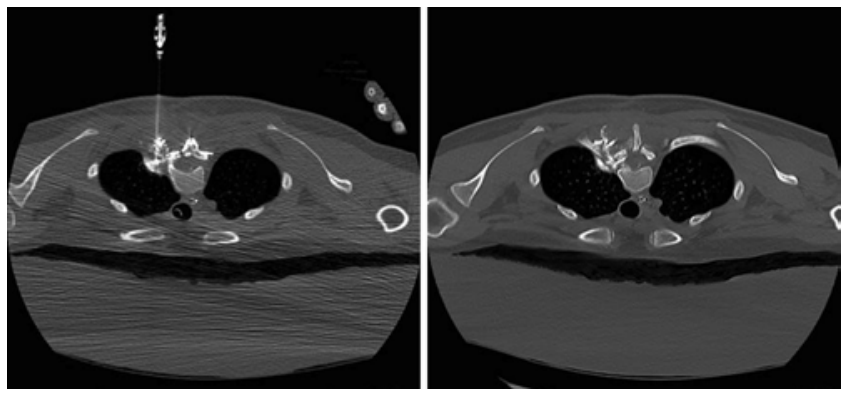

FIG. 5. CT chest axial images demonstrating the spinal needle accessing the mediastinal mass, with contrast filling the ventral epidural venous malformation and the mediastinal malformation, showing clear communication between the 2 compartments (left), and the mediastinal mass already decreased in size following the injection of the sclerosing agent, and more apparent filling of the ventral epidural venous malformation (right).

These are particularly rare in the pediatric age group, ${ }^{29}$ and are known to occur over a range of 15-79 years of age. ${ }^{16}$

The ISSVA classification was updated in April 2014 and has subclassified venous malformations as common, familial cutaneo-mucosal, blue rubber bleb nevus (Bean) syndrome, glomuvenous malformation, cerebral cavernous malformation, and other. ${ }^{13}$ The child in this report had no evidence of blue rubber bleb nevus (no blue rubber nevi), Klippel-Trénaunay (no congenital overgrowth of soft tissue and bone, of an extremity or otherwise), or Maffucci syndrome (absence of multiple enchondromas or soft-tissue venous malformations). The recently described CLOVES syndrome, which stands for congenital lipomatous overgrowth, vascular malformations, epidermal nevi, and scoliosis/skeletal/spinal anomalies, can be associated with fast-flow vascular malformations. ${ }^{1,28}$ Although this patient did have moderate epidural lipomatosis, she did not meet other criteria for CLOVES syndrome.' A highflow vascular lesion was excluded in this patient based on angiography findings.

The presented case was likely a sporadic common venous malformation. The use of oral contraceptives for amenorrhea 6 months prior to the development of the neurological symptoms may have precipitated enlargement of the malformation with subsequent development of the syrinx. Venous malformations are known to enlarge in puberty under the influence of hormones, specifically follicle-stimulating hormone and growth hormone..$^{10}$

\section{Clinical Presentation and Imaging}

Our patient presented several times with symptoms referable to the venous malformation. The initial presentation of persistent cough and neck pain may have been from compression of the mediastinal structures by the malformation. We believe that the Chiari malformation became symptomatic in 2005 secondary to effacement of the subarachnoid space by the venous malformation. Supportive evidence of this hypothesis is the fact that the subarachnoid space became so widely patent after the subtotal resection of the venous malformation, decompressing the patient's pituitary gland and allowing for the resumption of normal menses. Her cervicomedullary junction 

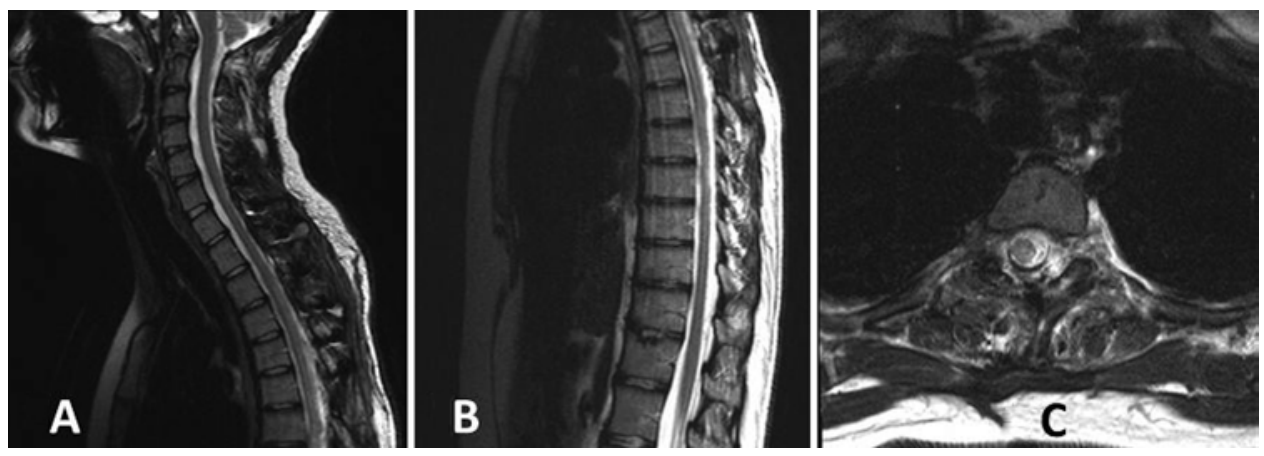

FIG. 6. A and B: Sagittal T2-weighted MR images of the cervical (A) and thoracic (B) spine obtained 6 months postoperatively. The syrinx has resolved. C: Axial T2-weighted MR image at the level of the mediastinal mass (T1-2), demonstrating its resolution.

had much more ample CSF surrounding it at this time, as well. The third presentation, with the insidious onset of neurogenic claudication, is likely secondary to the development of a syrinx in the spinal cord in the area of the epidural venous malformation, though it could be secondary to compression of the spinal cord by the malformation or venous hypertension. The clinical presentation of a venous malformation can include pain, which is often sudden in onset and secondary to thrombosis or hemorrhage, a presentation distinct from our patient's. Other symptoms are referable to the location of the malformation ${ }^{2,5-7,22}$ and can include radiculopathy and myelopathy. Transforaminal mediastinal extension of epidural dorsal thoracic spinal venous malformations ("dumbbell lesions") has been reported previously, and the negative thoracic cavity pressure has been postulated to facilitate the growth of these malformations toward the pleural cavity. ${ }^{16}$

On MRI, the vascular malformation was hypointense on T1-weighted images, hyperintense on T2-weighted images, and brilliantly enhanced with contrast administration. Multiple large blood vessels were visible. The MRI features of intraspinal venous malformations are variable, as shown in reported cases. ${ }^{6,13,15,20,22}$ Lesions with hemorrhage, liquefaction of hematomas, or intravascular thrombosis can have different signal on MRI or heterogeneous enhancement. ${ }^{12,33}$ A precise preoperative diagnosis based on imaging features is often difficult. Digital subtraction angiography has no role in the management of venous malformations as they are not well visualized and cannot be embolized, ${ }^{11,25}$ though digital subtraction angiography can be helpful in ruling out other types of vascular malformations.

Histologically, spinal vascular lesions can be differentiated by pathological examination. Enlarged venous channels lined by a single layer of endothelial cells and sparse smooth muscle cells characterize venous malformations. ${ }^{32}$ Immunohistochemistry may work as an adjunct for the differential diagnosis. Immunostaining for CD34 has been recognized as the most suitable and reliable diagnostic marker of endothelial cells. The positivity for smooth muscle actin but negativity for epithelial membrane antigen in the vessel walls favors diagnosing endothelial cells over arachnoidal or ependymal cells. Somatic mutations in TIE2 have been implicated in $40 \%$ of sporadic venous malformations. ${ }^{17}$

\section{Management}

Since a venous malformation is histologically benign and usually well marginated, gross-total removal should be attempted during surgical exploration. ${ }^{21,22,24,27,31}$ For patients with lesions growing around vital structures (such as the vascular tree, spinal cord, or within the pleural cavity), total resection may come at the risk of serious complications. ${ }^{3}$

We resected the dorsal component of the venous malformation but did not attempt to resect the ventral component because retracting the spinal cord in this location carries a high risk of paralysis. An anterior approach had been ruled out by the general surgeons, who recommended sclerotherapy for the mediastinal component. Preoperative sclerotherapy was not attempted because of the potential to cause an acute increase in venous hypertension, possibly accompanied by hemorrhage and catastrophic neurological decline.

We achieved an excellent result with a combination of resection and sclerotherapy. The patient has no neurological complaints other than her baseline migraine headaches. The restoration of normal CSF dynamics decompressed the pituitary gland and led to the resumption of normal menses. The syrinx resolved, and the malformation is not visible on MRI as of July 2015.

\section{Conclusions}

An epidural spinal venous malformation with a mediastinal component is a rare entity. A multidisciplinary approach with resection and percutaneous sclerotherapy resulted in complete resolution of the venous hypertension and neurological symptoms.

\section{References}

1. Alomari AI, Chaudry G, Rodesch G, Burrows PE, Mulliken JB, Smith ER, et al: Complex spinal-paraspinal fast-flow lesions in CLOVES syndrome: analysis of clinical and imaging findings in 6 patients. AJNR Am J Neuroradiol 32:1812-1817, 2011

2. Andersson T, van Dijk JM, Willinsky RA: Venous manifestations of spinal arteriovenous fistulas. Neuroimaging Clin N Am 13:73-93, 2003

3. Badinand B, Morel C, Kopp N, Tran Min VA, Cotton F: Dumbbell-shaped epidural capillary hemangioma. AJNR Am J Neuroradiol 24:190-192, 2003 
4. Binkert CA, Kollias SS, Valavanis A: Spinal cord vascular disease: characterization with fast three-dimensional contrast-enhanced MR angiography. AJNR Am J Neuroradiol 20:1785-1793, 1999

5. Clarke MJ, Patrick TA, White JB, Cloft HJ, Krauss WE, Lindell EP, et al: Spinal extradural arteriovenous malformations with parenchymal drainage: venous drainage variability and implications in clinical manifestations. Neurosurg Focus 26(1):E5, 2009

6. Decker RE, San Augustin W, Epstein JA: Spinal epidural venous angioma causing foraminal enlargement and erosion of vertebral body. Case report. J Neurosurg 49:605-606, 1978

7. Dompmartin A, Vikkula M, Boon LM: Venous malformation: update on aetiopathogenesis, diagnosis and management. Phlebology 25:224-235, 2010

8. Garen PD, Sahn EE: Spinal cord compression in blue rubber bleb nevus syndrome. Arch Dermatol 130:934-935, 1994

9. Greene AK: Vascular anomalies: current overview of the field. Clin Plast Surg 38:1-5, 2011

10. Hakan T, Demir M, Aker F, Berkman M: Pregnancy-related spinal epidural capillary-cavernous haemangioma: magnetic resonance imaging and differential diagnosis. Australas Radiol 51:B6-B9, 2007

11. Hasan A, Guiot MC, Torres C, Marcoux J: A case of a spinal epidural capillary hemangioma: case report. Neurosurgery 68:E850-E853, 2011

12. Hatiboglu MA, Iplikcioglu AC, Ozcan D: Epidural spinal cavernous hemangioma. Neurol Med Chir (Tokyo) 46:455458,2006

13. Hui F, Trosselo MP, Meisel HJ, Alvarez H, Sequeira E, Lasjaunias P: Paraspinal arteriovenous shunts in children. Neuroradiology 36:69-73, 1994

14. Kamat AS, Aliashkevich AF: Spinal cord compression in a patient with blue rubber bleb nevus syndrome. J Clin Neurosci 20:467-469, 2013

15. Lee JW, Cho EY, Hong SH, Chung HW, Kim JH, Chang KH, et al: Spinal epidural hemangiomas: various types of MR imaging features with histopathologic correlation. AJNR Am J Neuroradiol 28:1242-1248, 2007

16. Li TY, Xu YL, Yang J, Wang J, Wang GH: Primary spinal epidural cavernous hemangioma: clinical features and surgical outcome in 14 cases. J Neurosurg Spine 22:39-46, 2015

17. Limaye N, Wouters V, Uebelhoer M, Tuominen M, Wirkkala $\mathrm{R}$, Mulliken JB, et al: Somatic mutations in angiopoietin receptor gene TEK cause solitary and multiple sporadic venous malformations. Nat Genet 41:118-124, 2009

18. Logue V: Angiomas of the spinal cord: review of the pathogenesis, clinical features, and results of surgery. J Neurol Neurosurg Psychiatry 42:1-11, 1979

19. Lowe LH, Marchant TC, Rivard DC, Scherbel AJ: Vascular malformations: classification and terminology the radiologist needs to know. Semin Roentgenol 47:106-117, 2012

20. Mascalchi M, Quilici N, Ferrito G, Mangiafico S, Scazzeri F, Torselli P, et al: Identification of the feeding arteries of spinal vascular lesions via phase-contrast MR angiography with three-dimensional acquisition and phase display. AJNR Am J Neuroradiol 18:351-358, 1997

21. Meisel HJ, Lasjaunias P, Brock M: Modern management of spinal and spinal cord vascular lesions. Minim Invasive Neurosurg 38:138-145, 1995

22. Nishimura Y, Hara M, Natsume A, Nakajima Y, Fukuyama $\mathrm{R}$, Wakabayashi T, et al: Spinal intradural cystic venous angioma originating from a nerve root in the cauda equina. $\mathbf{J}$ Neurosurg Spine 19:716-720, 2013
23. Ochiai D, Miyakoshi K, Yakubo K, Fukuiya T, Yoshimura Y: Familial blue rubber bleb nevus syndrome in pregnancy with spinal epidural involvement. Case Rep Obstet Gynecol 2013:141506, 2013

24. Oya S, Prayson RA, Lee JH: A tentorial venous hemangioma presenting as an extra-axial mass in the ambient cistern: a case report. J Neurol Surg Rep 73:37-40, 2012

25. Rahman A, Hoque SU, Bhandari PB, Abu Obaida AS: Spinal extradural cavernous haemangioma in an elderly man. BMJ Case Rep 2012:bcr2012006453, 2012

26. Rajah G, To CY, Sood S, Ham S, Altinok D, Poulik J, et al: Epidural spinal cord compression in a patient with blue rubber bleb nevus syndrome. J Neurosurg Pediatr 14:486-489, 2014

27. Rodesch G, Lasjaunias P: Spinal cord arteriovenous shunts: from imaging to management. Eur J Radiol 46:221-232, 2003

28. Sapp JC, Turner JT, van de Kamp JM, van Dijk FS, Lowry RB, Biesecker LG: Newly delineated syndrome of congenital lipomatous overgrowth, vascular malformations, and epidermal nevi (CLOVE syndrome) in seven patients. Am J Med Genet A 143A:2944-2958, 2007

29. Sarikaya-Seiwert S, Gierga K, Wessalowski R, Steiger HJ, Hänggi D: Solitary spinal epidural cavernous angiomas in children presenting with acute neurological symptoms caused by hemorrhage. J Neurosurg Pediatr 5:89-93, 2010

30. Sohn MJ, Lee DJ, Jeon SR, Khang SK: Spinal radiosurgical treatment for thoracic epidural cavernous hemangioma presenting as radiculomyelopathy: technical case report. Neurosurgery 64:E1202- E1203, 2009

31. Tomycz ND, Vora NA, Kanal E, Horowitz MB, Jovin TG: Intracranial arterialized venous angioma: case report with new insights from functional brain MRI. Diagn Interv Radiol 16:13-15, 2010

32. Vikkula M, Boon LM, Carraway KL III, Calvert JT, Diamonti AJ, Goumnerov B, et al: Vascular dysmorphogenesis caused by an activating mutation in the receptor tyrosine kinase TIE2. Cell 87:1181-1190, 1996

33. Zhong W, Huang S, Chen H, Sun H, Cai B, Liu Y, et al: Pure spinal epidural cavernous hemangioma. Acta Neurochir (Wien) 154:739-745, 2012

\section{Disclosures}

The authors report no conflict of interest concerning the materials or methods used in this study or the findings specified in this paper.

\section{Author Contributions}

Conception and design: Gandhoke, Hamilton, Greene. Acquisition of data: Gandhoke, Hamilton, Salvetti, Greene. Analysis and interpretation of data: Gandhoke, Yilmaz, Grunwaldt, Hamilton, Greene. Drafting the article: Gandhoke, Yilmaz, Hamilton, Greene. Critically revising the article: Gandhoke, Yilmaz, Grunwaldt, Hamilton, Greene. Reviewed submitted version of manuscript: all authors. Approved the final version of the manuscript on behalf of all authors: Gandhoke. Study supervision: Hamilton, Greene.

\section{Correspondence}

Gurpreet S. Gandhoke, Department of Neurological Surgery, University of Pittsburgh Medical Center, 200 Lothrop St., Ste. B-400, Pittsburgh, PA 15213.email: gandhokegs@upmc.edu. 